\title{
Evolution of the COPD Assessment Test score during chronic obstructive pulmonary disease exacerbations: Determinants and prognostic value
}

\author{
Darwin Feliz-Rodriguez MD1, Santiago Zudaire MD¹, Carlos Carpio MD¹, Elizabet Martínez MD¹, \\ Antonia Gómez-Mendieta MD¹, Ana Santiago MD¹, Rodolfo Alvarez-Sala MD ${ }^{1,2}$, Francisco García-Río MD ${ }^{1,2,3}$
}

D Feliz-Rodriguez, S Zudaire, C Carpio, et al. Evolution of the COPD Assessment Test score during chronic obstructive pulmonary disease exacerbations: Determinants and prognostic value. Can Respir J 2013;20(5):e92-e97.

BACKGROUND: An adequate evaluation of exacerbations is a primary objective in managing patients with chronic obstructive pulmonary disease (COPD).

OBJECTIVES: To define the profile of health status recovery during severe exacerbations of COPD using the COPD Assessment Test (CAT) questionnaire and to evaluate its prognostic value.

METHODS: Forty-five patients with previous COPD diagnoses who were hospitalized due to severe exacerbation(s) were included in the study. These patients were treated by their respective physicians following current recommendations; health status was assessed daily using the CAT questionnaire. The CAT score, spirometry and recurrent hospitalizations were recorded one and three months after hospital discharge.

RESULTS: Global initiative for chronic Obstructive Lung Disease (GOLD) stage was an independent determinant for increased CAT score during the first days of exacerbation with respect to postexacerbation values. From hospitalization day 5, the CAT score was similar to that obtained in the stable phase. Body mass index, GOLD stage and education level were related to health status recovery pattern. CAT score increase and the area under the curve of CAT recovery were inversely related to the forced expiratory volume in $1 \mathrm{~s}$ achieved three months after discharge $(\mathrm{r}=-0.606$; $\mathrm{P}<0.001$ and $\mathrm{r}=-0.532 ; \mathrm{P}<0.001$, respectively). Patients with recurrent hospitalizations showed higher CAT score increases and slower recovery. CONCLUSIONS: The CAT detects early health status improvement during severe COPD exacerbations. Its initial worsening and recovery pattern are related to lung function and recurrent hospitalizations.

Key Words: Chronic obstructive pulmonary disease; Exacerbation; Health status; Questionnaires; Prognostic; Recovery

Chronic obstructive pulmonary disease (COPD) is a growing cause of morbidity and mortality worldwide (1). The exercise-induced dyspnea and fatigue that accompany COPD, as well as its oftenpresent comorbidities, may lead to limitation of some activities of daily living $(2,3)$. Moreover, dyspnea and deconditioning profoundly restrict physical activity and are known to produce spiralling losses in global functioning and quality of life over time.

The clinical course of COPD is marked by frequent exacerbations $(4,5)$ that negatively affect patients, producing clinical and pulmonary function deterioration over the long term $(6,7)$. Moreover, severe exacerbations requiring hospitalization also decrease the quality of life and health status (8), and increase mortality (9).

In view of all of the above, an adequate evaluation of COPD exacerbations has become one of the primary objectives in treating these patients. To do so, it is necessary to develop instruments that enable the precise measurement of their progression and evolution. The COPD Assessment Test (CAT) is a short, validated, patientcompleted questionnaire that quantifies the impact of COPD on health status (10). The CAT questionnaire covers a broad range of
L'évolution de l'indice du test d'évaluation de la MPOC pendant les exacerbations de la maladie pulmonaire obstructive chronique : les déterminants et la valeur pronostique

HISTORIQUE : L'un des objectifs primaires de la prise en charge des patients ayant une maladie pulmonaire obstructive chronique (MPOC) consiste à procéder à une évaluation convenable des exacerbations.

OBJECTIFS : Définir le profil du rétablissement de l'état de santé pendant de graves exacerbations de la MPOC à l'aide du questionnaire CAT visant à évaluer la MPOC, et en déterminer la valeur pronostique.

MÉTHODOLOGIE : Quarante-cinq patients ayant déjà un diagnostic de MPOC, hospitalisés en raison d'une grave exacerbation, ont participé à l'étude. Leur médecin respectif les a traités conformément aux recommandations à jour. On a évalué leur état de santé tous les jours au moyen du questionnaire CAT. L'indice CAT, la spirométrie et les hospitalisations récurrentes ont été consignés un et trois mois après le congé initial de l'hôpital.

RÉSULTATS : Le stade de la Global initiative for Chronic Obstructive Lung Disease (GOLD) était un déterminant indépendant d'un indice CAT plus élevé pendant les premiers jours d'exacerbation sur le plan des valeurs après l'exacerbation. À compter du $5^{\mathrm{e}}$ jour d'hospitalisation, l'indice CAT était similaire à celui obtenu pendant la phase de stabilité. L'indice de masse corporelle, le stade GOLD et le niveau d'instruction étaient liés au profil de rétablissement de la santé. L'augmentation de l'indice CAT et la zone sous la courbe du rétablissement CAT étaient inversement proportionnels au volume expiratoire maximal par seconde obtenu trois mois après le congé $(\mathrm{r}=-0,606 ; \mathrm{P}<0,001$ et $\mathrm{r}=-0,532 ; \mathrm{P}<0,001$, respectivement). Les patients ayant subi des hospitalisations récurrentes présentaient des augmentations plus marquées de l'indice CAT et se rétablissaient plus lentement.

CONCLUSIONS : Le questionnaire CAT permet de déceler le début des améliorations de la santé pendant de graves exacerbations de la MPOC. Son bilan d'aggravation initiale et de rétablissement est lié à la fonction pulmonaire et aux hospitalisations récurrentes.

effects of COPD on patient health with very good measurement properties and is applicable to global use $(11,12)$.

Information regarding the usefulness of CAT in the clinical management of COPD patients remains limited. In particular, an increase in the CAT score of five units over a maximum of 40 has been described during COPD exacerbations $(10,13)$; however, neither the dynamics of the recovery over the course of successive days of hospitalization nor the prognostic value are known.

Our objectives were to define the profile of health status recovery during a severe COPD exacerbation using the CAT questionnaire and to identify determinant factors. We also attempted to evaluate the prognostic value of the CAT recovery pattern and of the increase during the initial days of hospitalization due to COPD exacerbation.

\section{METHODS}

\section{Patients}

Patients 40 to 80 years of age with severe COPD exacerbations who were consecutively admitted to the Respiratory Service at the Hospital Universitario La Paz (Paseo de la Castellana, Madrid, Spain) during the

${ }^{1}$ Servicio de Neumología, Hospital Universitario La Paz, IdiPAZ, Madrid; ${ }^{2}$ Universidad Autónoma de Madrid; ${ }^{3}$ CIBER de Enfermedades

Respiratorias (CIBERES), Palma de Mallorca, Spain

Correspondence: Dr Francisco García-Río, Servicio de Neumología, Hospital Universitario La Paz, Paseo de la Castellana, 261, Madrid 28046,

Spain. Telephone 34-63-991-1718, fax 34-91-207-1061, e-mail fgr01m@gmail.com 
period from January 1 to March 31, 2010 were selected. Because of the severity of illness at the time of admission, spirometry was not performed in the emergency room. The diagnosis of COPD was based on clinical history and previous spirometric criteria according to the Global initiative for chronic Obstructive Lung Disease (GOLD) guidelines (1). A COPD exacerbation was defined as an acute worsening of the patient's baseline dyspnea, cough and/or sputum production. All patients met the criteria for the admission to hospital because of severe COPD exacerbation (1).

Exclusion criteria included a history of asthma, any other active lung disease, mental or physical disability, and chest wall or neuromuscular diseases. All subjects provided written informed consent and the local ethics committee approved the study.

\section{Procedures}

During hospitalization, patients were treated by their respective physicians with controlled oxygen therapy, bronchodilators, systemic glucocorticosteroids and antibiotics, according to the GOLD recommendations (1). None of the patients presented criteria for noninvasive mechanical ventilation.

Patients were examined on admission to the emergency department by two residents who were supervised by a board-certified specialist in respiratory diseases. Information regarding anthropometric characteristics, alcohol consumption, smoking habits, education level, comorbidities and number of hospitalizations due to COPD exacerbations in the past year was recorded. Previous baseline spirometric values (up to three months) and current treatment were recorded. Baseline dyspnea was assessed by the modified Medical Research Council (MRC) scale. COPD severity was classified according to GOLD stage (1) and the age, dyspnea, and airflow obstruction (ADO) index (14).

Health status was assessed daily using the Spanish version of the COPD Assessment Test (CAT), which contains eight short, simple, patient-completed questions regarding respiratory or chest-related symptoms, such as cough or sensation of mucus accumulation or chest tightness, and also about more general complaints, such as disturbances in sleep or decreased energy levels and daily limitations resulting from the disease (10). Patients can choose a score from 0 to 5 for each item; the CAT has a scoring range from 0 to 40 , with higher scores representing poorer health status.

After hospital discharge, patients were evaluated at one and three months, while they were clinically stable. At these visits, health status was assessed by the CAT and spirometry was performed (MasterLab, Germany) according to current recommendations (15) and using the European Coal and Steel Community predicted values (16). The need for additional hospitalizations due to recurrent severe COPD exacerbation during the three-month follow-up was recorded.

\section{Statistical analysis}

Data are expressed as mean \pm SD for normally distributed variables, or as median and interquartile range (IQR) for non-normally distributed continuous variables, and as a percentage of the total number of cases studied for categorical variables. Comparisons between groups were performed using the Student's $t$, Mann-Whitney and $\chi^{2}$ tests.

The acute impact of exacerbation on health status was expressed by an increase in the CAT score during the first two days of hospitalization compared with the stable period (one and three months after discharge). Changes over time in the CAT score were assessed using a general linear model for repeated measurements (17), with sex, smoking habits, education level and GOLD stage as intersubject factors, and age, body mass index (BMI), pack-years smoking, MRC and ADO index as covariates. Multiple comparisons were based on estimated marginal means and Dunnett's T3 adjustment.

Because improvement in health status was expected to be nonlinear, area under the curve (AUC) was used as the best estimate of the mean change in CAT score. The AUC was calculated using the trapezium rule $(\mathrm{t} 2-\mathrm{t} 1) \cdot(\mathrm{y} 1+\mathrm{y} 2) / 2$ and then divided by the total number of days in the study (18). To provide an estimation of early improvement, AUC was calculated for the third and fifth days of hospitalization.

\section{TABLE 1}

\section{General characteristics of the chronic obstructive pulmonary disease patients}

\begin{tabular}{|c|c|}
\hline Male/female, $n / n$ & $31 / 14$ \\
\hline Age, years, mean \pm SD & $71 \pm 10$ \\
\hline Height, $\mathrm{cm}$, mean $\pm \mathrm{SD}$ & $166 \pm 8$ \\
\hline Weight, $\mathrm{kg}$, mean $\pm \mathrm{SD}$ & $72 \pm 11$ \\
\hline Body mass index, $\mathrm{kg} / \mathrm{m}^{2}$, mean $\pm \mathrm{SD}$ & $26.2 \pm 4.4$ \\
\hline \multicolumn{2}{|l|}{ Smoking status } \\
\hline Current & $25(56)$ \\
\hline Former & $19(42)$ \\
\hline Never & $1(2)$ \\
\hline Pack-years smoking, mean \pm SD & $51 \pm 27$ \\
\hline \multicolumn{2}{|l|}{ Education level } \\
\hline Primary & $16(36)$ \\
\hline Secondary & $18(40)$ \\
\hline University & $11(24)$ \\
\hline Hospitalizations in the past 12 months, mean \pm SD & $1.8 \pm 1.2$ \\
\hline \multicolumn{2}{|l|}{ Previous baseline spirometry } \\
\hline Postbronchodilator FVC, $\%$ predicted, mean \pm SD & $81 \pm 21$ \\
\hline Postbronchodilator $\mathrm{FEV}_{1}, \%$ predicted, mean $\pm \mathrm{SD}$ & $51 \pm 17$ \\
\hline Postbronchodilator $\mathrm{FEV}_{1} / \mathrm{FVC}$, mean $\pm \mathrm{SD}$ & $0.51 \pm 0.15$ \\
\hline Medical Research Council dyspnea scale, mean \pm SD & $2.9 \pm 0.9$ \\
\hline$A D O$ index, mean $\pm S D$ & $5.6 \pm 1.7$ \\
\hline Short-acting beta-adrenergic agonists & $4(9)$ \\
\hline Long-acting beta-adrenergic agonists & $36(82)$ \\
\hline Anticholinergics & $40(91)$ \\
\hline Inhaled corticosteroids & $26(58)$ \\
\hline Long-term oxygen therapy & $12(27)$ \\
\hline \multicolumn{2}{|l|}{ Comorbidities } \\
\hline Hypertension & $19(44)$ \\
\hline Ischemic heart disease & $12(27)$ \\
\hline Diabetes mellitus & $15(35)$ \\
\hline Sleep apnea-hypopnea syndrome & $5(13)$ \\
\hline
\end{tabular}

Data presented as $n$ (\%) unless otherwise indicated. ADO Age, dyspnea, and airflow obstruction; FEV 1 Forced expiratory volume in $1 \mathrm{~s}$; FVC Forced vital capacity

The relationship among variables was analyzed using the Pearson correlation and multiple linear regression analysis. Results were considered to be statistically significant at $\mathrm{P}<0.05$. Analyses were performed using SPSS version 13.0 (IBM Corporation, USA).

\section{RESULTS}

Forty-five patients hospitalized for severe COPD exacerbation (31 men and 14 women) were included in the study; $56 \%$ were current smokers. According to the GOLD criteria for COPD classification, 13\% of the patients were in stage I, 29\% in stage II, 22\% in stage III and 36\% in stage IV. More detailed information about the patients' characteristics is presented in Table 1.

The mean CAT score during the first two days of hospitalization was higher than the mean at one and three months after hospital discharge $(22.8 \pm 4.9$ versus $15.6 \pm 4.5 ; \mathrm{P}<0.001)$, which corresponds to a mean increase of $6.5 \pm 3.9$ points. The items whose scores experienced major deterioration during the severe exacerbation were "I never cough/I cough all the time" $(1.0 \pm 0.9)$ and "I have lots of energy/I have no energy at all" $(1.0 \pm 1.7)$. The increase in the CAT score induced by the exacerbation was lower in patients with long-term oxygen therapy $(3.9 \pm 4.0$ versus $8.5 \pm 4.2 ; \mathrm{P}=0.016)$ and in patients with very severe disease. In fact, change in CAT score was lower in patients with stage IV COPD $(4 \pm 4)$ than in patients with stages I to III COPD $(7 \pm 2,8 \pm 4$ and $7 \pm 3$, respectively; $\mathrm{P}=0.037)$. Moreover, the increase in the CAT 


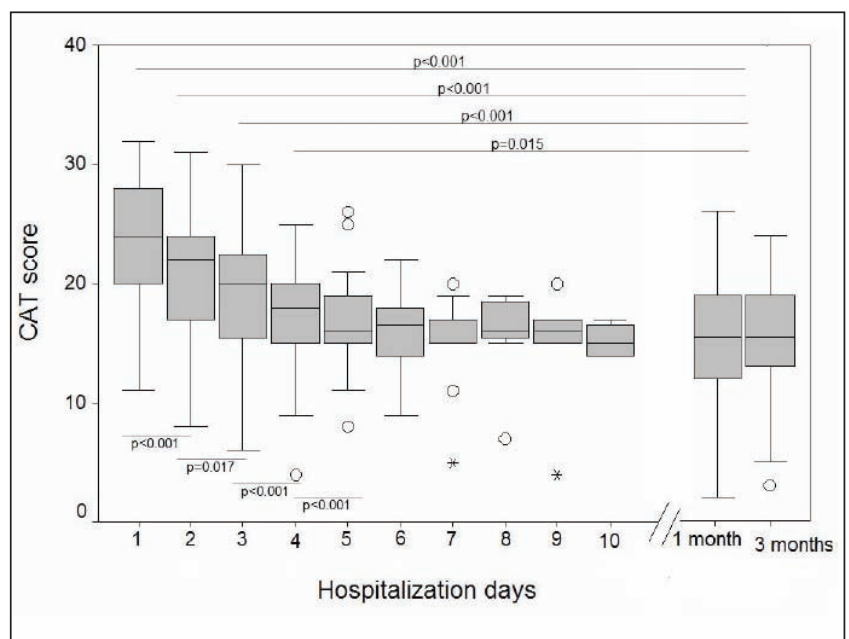

Figure 1) Box-and-whisker plots of the evolution of COPD Assessment Test (CAT) score during hospitalization and one and three months after hospital discharge in patients with chronic obstructive pulmonary disease. The top of the box represents the 75th percentile, the bottom of the box represents the 25 th percentile, and the line in the middle represents the 50th percentile. The whiskers represent the highest and lowest values that are not outliers or extreme values. Outliers (values that are between 1.5 and 3 times the interquartile range) and extreme values (values that are $>3$ times the interquartile range) are represented by circles and asterisks beyond the whiskers. Comparisons between days perfromed using a general linear model with repeated measures

\section{TABLE 2}

Analysis of within-subject effects of time and its interaction with other variables on CAT score during the first five days of hospitalization for COPD exacerbation

\begin{tabular}{lccccc}
\hline Source & $\begin{array}{c}\text { Type III Sum } \\
\text { of squares }\end{array}$ & df & square & $\mathbf{F}$ & $\mathbf{P}$ \\
\hline Time & 31.839 & 5 & 6.368 & 2.762 & 0.040 \\
Time*age & 15.762 & 5 & 3.152 & 1.367 & 0.270 \\
Time*sex & 18.56 & 5 & 3.712 & 1.61 & 0.194 \\
Time*BMI & 72.943 & 5 & 14.589 & 6.329 & 0.001 \\
Time*smoking habit & 22.773 & 10 & 2.277 & 0.988 & 0.479 \\
Time*pack-years & 13.541 & 5 & 2.708 & 1.175 & 0.349 \\
Time*education level & 60.821 & 10 & 6.082 & 2.638 & 0.024 \\
Time*MRC & 25.483 & 5 & 5.097 & 2.211 & 0.085 \\
Time*GOLD & 107.635 & 15 & 7.176 & 3.113 & 0.006 \\
Time*ADO index & 115.610 & 30 & 3.854 & 0.877 & 0.652 \\
\hline ADO & & &
\end{tabular}

ADO Age, dyspnea, and airflow obstruction; BMI Body mass index; CAT COPD Assessment Test; COPD Chronic obstructive pulmonary disease; GOLD Global initiative for chronic Obstructive Lung Disease; MRC Medical Research Council

score was inversely related to pack-years smoking ( $r=-0.334 ; \mathrm{P}=0.027)$. No relationship was found with sex, age, BMI, morbidity, educational level, MRC, ADO index or time since last exacerbation. In a multiple linear regression analysis, only the baseline GOLD stage was retained as an independent determinant for the increase in the CAT score during severe exacerbation: CAT increase $=10.236-1.347 \times$ GOLD stage $(1$ $=$ mild, $2=$ moderate, $3=$ severe and $4=$ very severe $)\left(r^{2}=0.298\right.$, $\mathrm{P}=0.013$ ).

Figure 1 illustrates the evolution of the CAT score during hospitalization, as well as at one and three months after hospital discharge. The within-subject test suggests that there is a significant time effect. Significant differences are observed in the first four days of hospitalization, showing a CAT score higher than the mean at one and three months after hospital discharge. From the fifth day of hospitalization, significant differences were not detected compared with the score
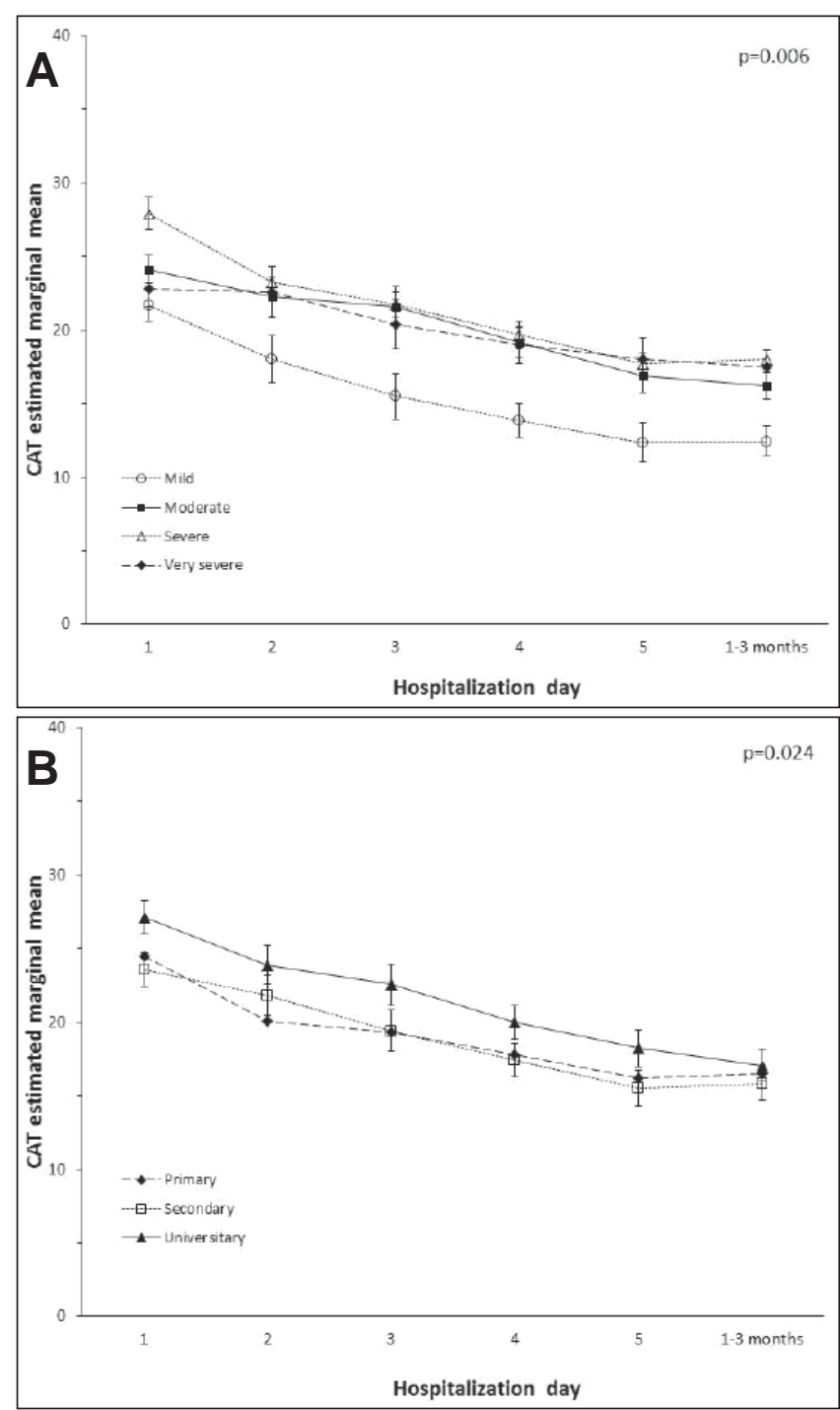

Figure 2) Mean ( \pm SEM) COPD Assessment Test (CAT) scores in chronic obstructive pulmonary disease (COPD) patients during the first days of hospitalization and after hospital discharge according to COPD severity (A) and education level (B). Using repeated measurement analysis, a time effect for Global initiative for chronic Obstructive Lung Disease level $(P=0.006)$ and education level $(P=0.024)$ was found

obtained in stable phase. Moreover, the interaction of time and some intersubject variables are significant (Table 2). BMI, GOLD stage and education level were identified as independent factors related to different CAT recovery rates in the initial days of hospitalization. Figure 2 shows that the GOLD stage and education level groups vary over time, but that the groups have nonparallel lines that decrease in slope over time. The AUC analysis of the CAT score during the first few days of hospitalization confirms that patients with mild COPD or nonuniversity educational level experienced a faster health status recovery (Table 3).

The CAT items that show a faster recovery are those related to breathlessness, sputum and fatigue. In contrast, the item of confidence is the slowest to recover (Table 4).

The acute increase in the CAT score during the initial days of the exacerbation in relation to the postexacerbation values and the early recovery pattern were related to the postbronchodilator forced expiratory volume in $1 \mathrm{~s}\left(\mathrm{FEV}_{1}\right)$ measured three months after hospital discharge. The CAT increase was inversely proportional to $\mathrm{FEV}_{1}$ $(r=-0.606 ; P<0.001)$ (Figure 3A). In fact, the area under the curve of CAT recovery during the first five days of hospitalization was also 
TABLE 3

Comparisons of area under the curve (AUC) of CAT score during the first three and five days of hospitalization according to COPD severity or educational level

\begin{tabular}{lcc}
\hline & AUC 3 days & AUC 5 days \\
\hline GOLD stage & $18.2 \pm 1.9$ & \\
Mild & $20.3 \pm 5.2$ & $16.0 \pm 2.1$ \\
Moderate & $23.4 \pm 4.6^{\star}$ & $21.2 \pm 5.1^{*}$ \\
Severe & $20.8 \pm 3.3$ & $21.8 \pm 4.6^{\dagger}$ \\
Very severe & 0.101 & $20.1 \pm 2.5^{\star}$ \\
P (ANOVA) & & 0.048 \\
Education & $19.0 \pm 4.0$ & $19.2 \pm 4.3^{\ddagger}$ \\
Primary & $22.3 \pm 3.5$ & $19.9 \pm 4.6^{\ddagger}$ \\
Secondary & $22.0 \pm 6.3$ & $23.0 \pm 4.2$ \\
University & 0.103 & 0.035 \\
P (ANOVA) & & \\
\hline
\end{tabular}

Data presented as mean $\pm S D$. ${ }^{*} P<0.05$ versus mild Global initiative for chronic Obstructive Lung Disease (GOLD) stage; ${ }^{\dagger} P<0.01$ versus mild GOLD stage; ${ }^{\ddagger} P<0.05$ versus university educational leve. CAT COPD Assessment Test; COPD Chronic obstructive pulmonary disease

\section{TABLE 4}

Mean differences for the COPD Assessment Test questionnaire items between the third or fifth hospitalization day and the day of admission

\begin{tabular}{|c|c|c|}
\hline Item & $\Delta$ 3rd day & $\Delta 5$ th day \\
\hline never cough/l cough all the time & $-0.91 \pm 1.19$ & $-1.55 \pm 1.37$ \\
\hline $\begin{array}{l}\text { I have no phlegm (mucus) in my chest at all / } \\
\text { My chest is completely full of phlegm } \\
\text { (mucus) }\end{array}$ & $-1.23 \pm 1.41$ & $-1.82 \pm 0.87$ \\
\hline $\begin{array}{l}\text { My chest does not feel tight at all / My chest } \\
\text { feels very tight }\end{array}$ & $-0.45 \pm 0.80$ & $-1.00 \pm 0.77$ \\
\hline $\begin{array}{l}\text { When I walk up a hill or one flight of stairs I } \\
\text { am not breathless / When I walk up a hill or } \\
\text { one flight of stairs I am very breathless }\end{array}$ & -1.32 & -1 \\
\hline $\begin{array}{l}\text { I am not limited doing any activities at home / } \\
\text { I am very limited doing activities at home }\end{array}$ & $-0.86 \pm 0.88$ & $-1.27 \pm 1.10$ \\
\hline I am confident leaving my home despite my & $0.00 \pm 1.34$ & $-0.55 \pm 1.51$ \\
\hline
\end{tabular}

lung condition / I am not at all confident

leaving my home because of my lung condition

I sleep soundly / I don't sleep soundly $-0.45 \pm 1.01-0.73 \pm 1.55$ because of my lung condition

I have lots of energy / I have no energy at all $\quad-1.09 \pm 1.11 \quad-1.64 \pm 1.28$ Data presented as mean $\pm S D$. $\triangle$ Difference; COPD Chronic obstructive pulmonary disease

inversely related to $\mathrm{FEV}_{1}(\mathrm{r}=-0.532 ; \mathrm{P}<0.001)$ (Figure 3B), namely, patients who achieved a higher CAT score during the first days of the exacerbation reached a lower $\mathrm{FEV}_{1}$.

During the three months of follow-up, six patients once again required hospitalization for a recurrent COPD exacerbation. These patients had higher CAT score increases during the initial days of hospitalization $(7.0 \pm 3.6$ versus $2.0 \pm 9.1 ; \mathrm{P}=0.030)$ and higher AUC the first five days of exacerbation $(22.37 \pm 0.57$ versus $20.1 \pm 5.25$; $\mathrm{P}=0.046)$.

\section{DISCUSSION}

Our results show that the CAT questionnaire detected early changes in the health status of COPD patients who were hospitalized due to severe exacerbation. They also identify some determinant factors of the health status recovery pattern and show that both early worsening and the recovery pattern in the first five days of hospitalization are related to lung function reached after discharge and to the development of recurrent hospitalizations in the following three months.

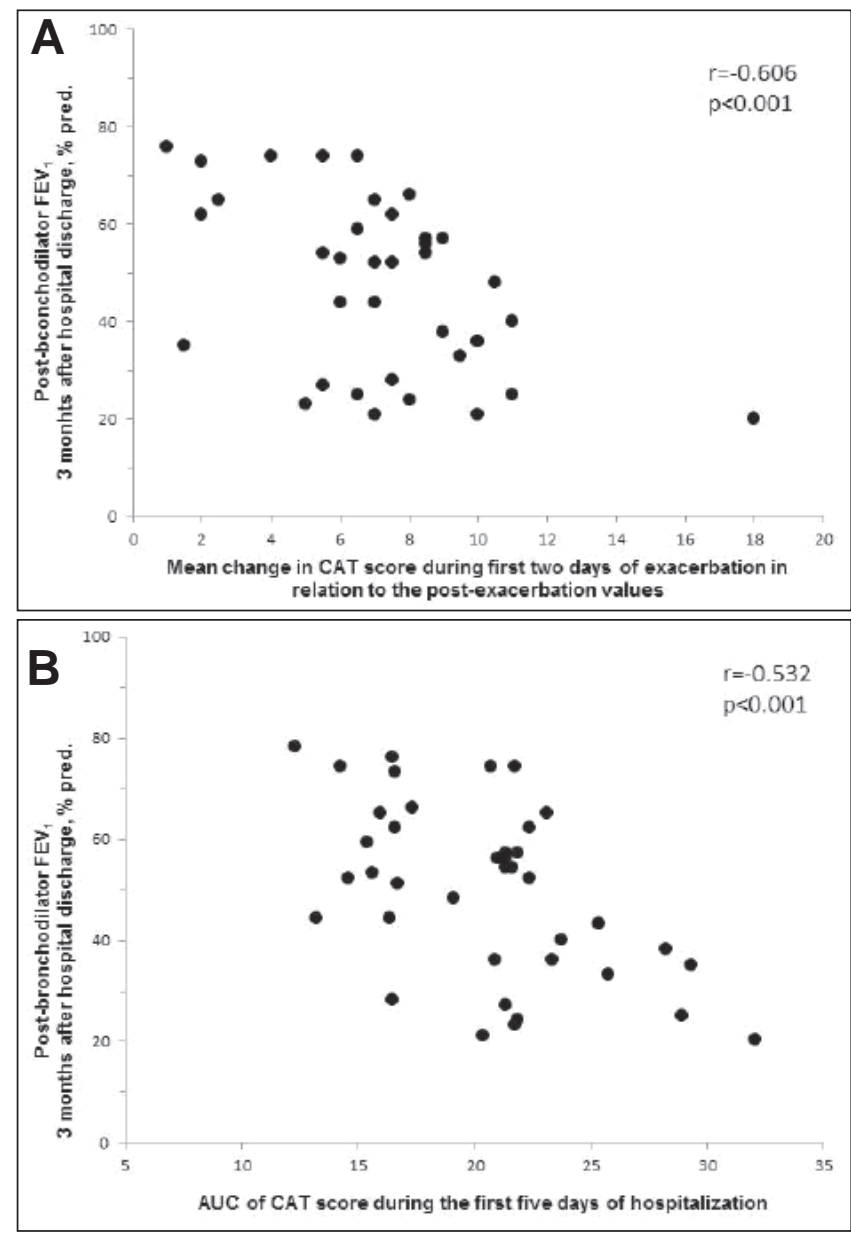

Figure 3) Relationship between the postbronchodilator forced expiratory volume in $1 \mathrm{~s}\left(\mathrm{FEV}_{1}\right)$ reached three months after hospital discharge $(\mathrm{A})$ and the mean COPD Assessment Test (CAT) score increase during the first two days of exacerbation in relation to the postexacerbation values (B) and the area under the curve (AUC) of CAT recovery during the first five days of hospitalization. COPD Chronic obstructive pulmonary disease; pred Predicted

These results could present a new scenario for the application of CAT, which was initially developed as a simple instrument for quantifying the symptom burden of COPD in routine practice $(10,19)$.

There is some information about the increase in CAT score in patients with mild to moderate exacerbations $(10,11,20,21)$ although to our knowledge, its behaviour in severe exacerbations has not been described. In the CAT validation study, the difference between stable and exacerbation patients was 4.7 units (10). In a later European study (11), the difference between stable and mild to moderate exacerbation was 5.1 units, while in our patients, the increase between stable and severe exacerbation was $6.5 \pm 3.9$ units. It appears obvious that the magnitude in the difference corresponds directly with the severity of the COPD exacerbation.

An outstanding result from our study is the description of health status recovery pattern, assessed by the CAT questionnaire, during a severe COPD exacerbation. The improvement in health status is evident in the first days of hospitalization. Although the minimum clinically important difference (MCID) for the CAT has not yet been established, the four-unit MCID for the St George's Respiratory Questionnaire (SGRQ) corresponds to a value of 1.6 units for the CAT MCID $(19,20)$. According to this criterion, the CAT score improvement with regard to the previous day surpassed the MCID in $67 \%$ of the patients on the second day of hospitalization, in $56 \%$ on the third day, in $52 \%$ on the fourth day and in $28 \%$ on the fifth day. 
This finding contrasts with the classic vision, which considers that a patient often requires several weeks to recover from an exacerbation (22).

BMI, level of education and the GOLD stage have been identified as the main determinants of the CAT recovery pattern during severe COPD exacerbations. To our knowledge, there are no previous studies that would allow us to contrast these findings, but there is some information about the factors related to CAT score in stable patients.

In a study that summarized the performance of the CAT questionnaire in a large population of stable COPD patients from primary care in seven European countries covering all severities of airway obstruction (11), mean CAT scores were related to severity of airway obstruction with a weak negative relationship with $\mathrm{FEV}_{1}$. Our results also show that the COPD patients with lowest lung function impairment recover their health status more quickly during a severe exacerbation. In contrast, in COPD patients participating in pulmonary rehabilitation programs, Dodd et al (20) recently reported that the improvement in CAT was not associated with baseline dyspnea or airflow obstruction. It is possible that respiratory rehabilitation and exacerbations may not have an impact on the same facets of the illness; therefore, their behaviour may not be similar.

Although a low BMI is a recognized risk factor for mortality in COPD patients (23), in our patients, excess weight was associated with a slower improvement in health status during a severe exacerbation. In this case, the negative impact of a high BMI on lung function (24) likely prevails against the systemic effects of weight loss. Our information also shows that patients with a low educational level experience accelerated improvement in their health status. Although more information is needed to appropriately assess this finding, it has been recently demonstrated that patients with lower educational levels have poorer health-related quality of life (25). We speculate that these patients are more sensitive to an intensification of the level of health care during hospitalization.

Finally, our results suggest that the increase in the CAT score during the first two days of the exacerbation in relation to the postexacerbation values and its recovery pattern may have some prognostic value. Previously, it had been reported that a sustained worsening of symptoms during a COPD exacerbation can also have a significant impact on quality of life and mortality $(26,27)$. Although its effect on lung function was less known, our results show a clear relationship. There are several mechanisms that may explain the association between slower recovery of health status during a severe exacerbation and lower lung function results. Patients with poorer health status recovery spent a longer time in hospital, which may lead to a larger decline in $\mathrm{FEV}_{1}$. A poorer health status recovery may also reflect insufficient treatment that does not adequately control airway inflammation. Moreover, persistent bacterial colonization of the airways has been related to the severity of the underlying airflow obstruction (28) and to a higher risk of exacerbations (29). It is known that COPD patients with frequent exacerbations experienced a significantly greater decline in $\mathrm{FEV}_{1}$ than patients who experienced infrequent exacerbations (7).

The evolution of the CAT score during hospitalization also appears to identify patients who will experience a recurrent exacerbation. This finding is concordant with the results reported by Spencer and Jones (22), who demonstrated that, in patients with moderate COPD exacerbations, the SGRQ scores improved more rapidly in patients with no additional exacerbations during the following six months.

Our study had several limitations that must be addressed. The sample size was small for an observational study, although it was sufficient to detect significant differences. The unicentric nature of the study limits the generalization of our results, mainly for CAT versions in other languages. The absence of parallel information with other quality-of-life questionnaires does not allow us to assess the concurrent validity to discriminate whether the detection of an early improvement in health status is specific to the CAT questionnaire or whether other questionnaires are capable of such detection. The fact that baseline CAT scores were not ascertained in the cohort before COPD exacerbation is another weakness of our study. However, in previous studies, CAT scores during periods of stability postexacerbation were also used to estimate the baseline state $(10,13)$. Our results refer to severe exacerbations that require hospitalization; hence, they may not be able to be extrapolated to other types of exacerbations. Finally, it is necessary to concede that the CAT questionnaire was not designed to detect changes in health status on a daily basis. Our results have shown the capability of the CAT to detect early improvements in health status during severe COPD exacerbations and may, therefore, present a new scenario for its application; however, caution is advised when interpreting daily variations in CAT scores.

\section{CONCLUSION}

Our results show that the CAT questionnaire offers the detection of early improvements in the health status during hospitalization for COPD exacerbation, and that its initial increase and recovery pattern are related to lung function after discharge as well as recurrent hospitalizations. The widespread adoption of the CAT as a substitute for more time-consuming questionnaires would bring this type of assessment into routine clinical practice, and it may play a role in monitoring the evolution of patients hospitalized for severe COPD exacerbations.

\section{REFERENCES}

1. Rabe KF, Hurd S, Anzueto A, et al. Global strategy for the diagnosis, management, and prevention of chronic obstructive pulmonary disease: GOLD Executive Summary. Am J Respir Crit Care Med 2007;176:532-55.

2. Garcia-Rio F, Lores V, Mediano O, et al. Daily physical activity in patients with chronic obstructive pulmonary disease is mainly associated with dynamic hyperinflation. Am J Respir Crit Care Med 2009;180:506-12.

3. Watz H, Waschki B, Boehme C, Claussen M, Meyer T, Magnussen H. Extrapulmonary effects of chronic obstructive pulmonary disease on physical activity: A cross-sectional study. Am J Respir Crit Care Med 2008;177:743-51.

4. Pauwels R, Calverley P, Buist AS, et al. COPD exacerbations: The importance of a standard definition. Respir Med 2004;98:99-107.

5. Hurst JR, Wedzicha JA. What is (and what is not) a COPD exacerbation: Thoughts from the new GOLD guidelines. Thorax 2007;62:198-99.

6. Cote CG, Dordelly LJ, Celli BR. Impact of COPD exacerbations on patient-centered outcomes. Chest 2007;131:696-704.

7. Donaldson GC, Seemungal TAR, Bhowmik A, Wedzicha JA. Relationship between exacerbation frequency, lung function decline in chronic obstructive pulmonary disease. Thorax 2002;57:847-52.

8. Aaron SD, Vandemheen KL, Clinch JJ, et al. Measurement of short-term changes in dyspnea, disease-specific quality of life following an acute COPD exacerbation. Chest 2002;121:688-96.

9. Soler-Cataluña JJ, Martínez-García MA, Román Sánchez P, Salcedo E, Navarro M, Ochando R. Severe acute exacerbations, mortality in patients with chronic obstructive pulmonary disease. Thorax 2005;60:925-31.

10. Jones PW, Harding G, Berry P, Wiklund I, Chen WH, Leidy NK. Development, first validation of the COPD Assessment Test. Eur Respir J 2009;34:648-54.

11. Jones PW, Brusselle G, Dal Negro RW, et al. Properties of the COPD Assessment Test (CAT) in a cross-sectional European study. Eur Respir J 2011;38:29-35.

12. Kelly JL, Bamsey O, Smith C, et al. Health status assessment in routine clinical practice: The chronic obstructive pulmonary disease assessment test score in outpatients. Respiration 2012;84:193-99.

13. Mackay AJ, Donaldson GC, Patel ARC, Jones PW, Hurst JR, Wedzicha JA. Usefulness of the chronic obstructive pulmonary disease assessment test to evaluate severity of COPD exacerbations. Am J Respir Crit Care Med 2012;185:1218-24.

14. Puhan MA, Garcia-Aymerich J, Frey M, et al. Expansion of the prognostic assessment of patients with chronic obstructive pulmonary disease: The updated BODE index, the ADO index. Lancet 2009;374:704-11. 
15. Miller MR, Hankinson J, Brusasco V, et al. Standardization of spirometry. Eur Respir J 2005;26:319-38.

16. Quanjer PH, Trammeling GJ, Cotes JE, Pedersen OF, Peslin R, Yernault JC. Lung volumes, forced ventilatory flows. Report Working Party Standardization of Lung Function Tests. European Community for Steel, Coal. Official Statement of the European Respiratory Society. Eur Respir J 1993;6:5s-40s.

17. Snijders T, Bosker R. Multilevel Analysis: An Introduction to Basic, Advanced Multilevel Modeling. London: Sage, 1999.

18. Matthews JNS, Altman DG, Campbell MJ, Royston P. Analysis of serial measurements in medical research. Br Med J 1990;300:230-5.

19. Jones PW, Price D, van der Molen T. Role of clinical questionnaires in optimizing everyday care of chronic obstructive pulmonary disease. Int J COPD 2011;6:289-96.

20. Dodd JW, Hogg L, Nolan J, et al. The COPD assessment test (CAT): Response to pulmonary rehabilitation. A multicentre, prospective study. Thorax 2011;66:425-9.

21. Jones PW, Harding G, Wiklund I, Yu R, Kline Leidy N. The COPD Assessment Test ${ }^{\mathrm{TM}}$ (CAT) can detect changes in health status during recovery from acute exacerbations. Am J Respir Crit Care Med 2010;181:A5954.

22. Spencer S, Jones PW. Time course of recovery of health status following an infective exacerbation of chronic bronchitis. Thorax 2003;58:589-93.
23. Domingo-Salvany A, Lamarca R, Ferrer M, et al. Health related quality of life, mortality in male patients with chronic obstructive pulmonary disease. Am J Respir Crit Care Med 2002;166:680-5.

24. Cotes JE, Chinn DJ, Reed JW. Body mass, fat percentage, and fat free mass as reference variables for lung function: Effects on terms for age, sex. Thorax 2001;56:839-44.

25. Miravitlles M, Naberan K, Cantoni J, Azpeitia A. Socioeconomic status, health-related quality of life of patients with chronic obstructive pulmonary disease. Respiration 2011;82:402-8.

26. Kessler R, Stahl E, Vogelmeier C, et al. Patient understanding, detection, and experience of COPD exacerbations: An observational, interview based study. Chest 2006;130:133-42.

27. Esteban C, Quintana JM, Moraza J, et al. Impact of hospitalisations for exacerbations of COPD on health-related quality of life. Respir Med 2009;103:1201-8.

28. Miravitlles M, Espinosa C, Fernandez-Laso E, Martos JA, Maldonado JA, Gallego M. Relationship between bacterial flora in sputum, functional impairment in patients with acute exacerbations of COPD. Chest 1999;116:40-6.

29. Patel IS, Seemungal TA, Wilks M, Lloyd-Owen SJ, Donaldson GC, Wedzicha JA. Relationship between bacterial colonisation, the frequency, character, severity of COPD exacerbations. Thorax 2002;57:759-64. 


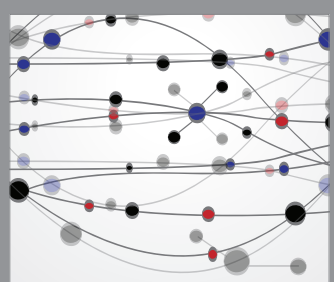

The Scientific World Journal
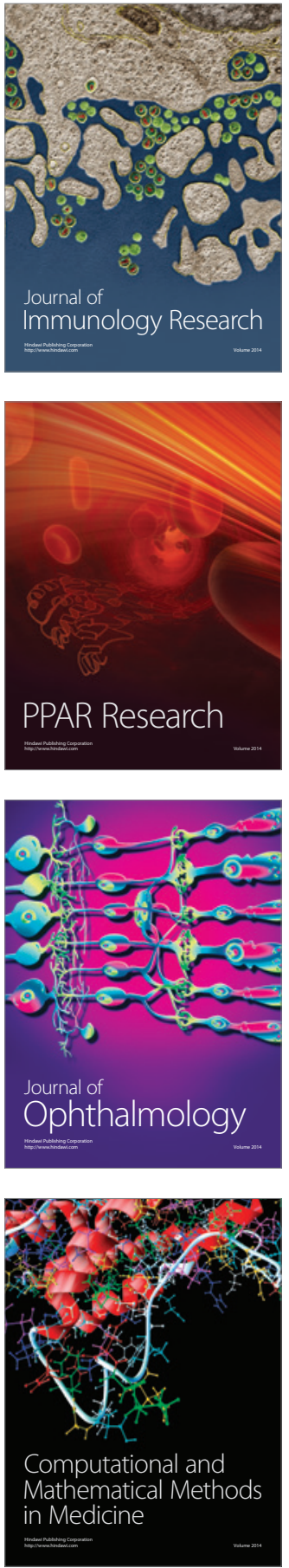

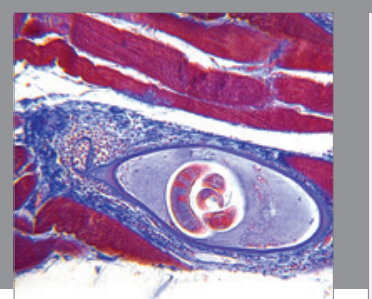

Gastroenterology Research and Practice

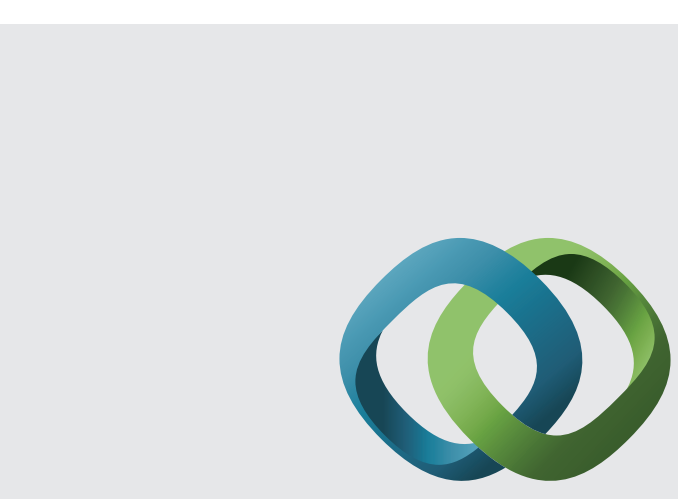

\section{Hindawi}

Submit your manuscripts at

http://www.hindawi.com
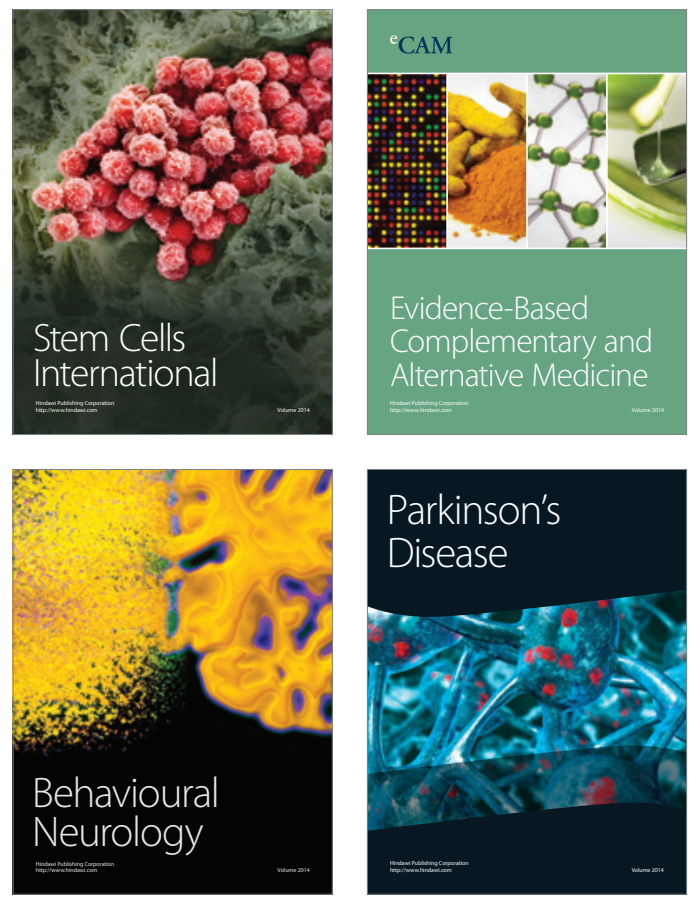
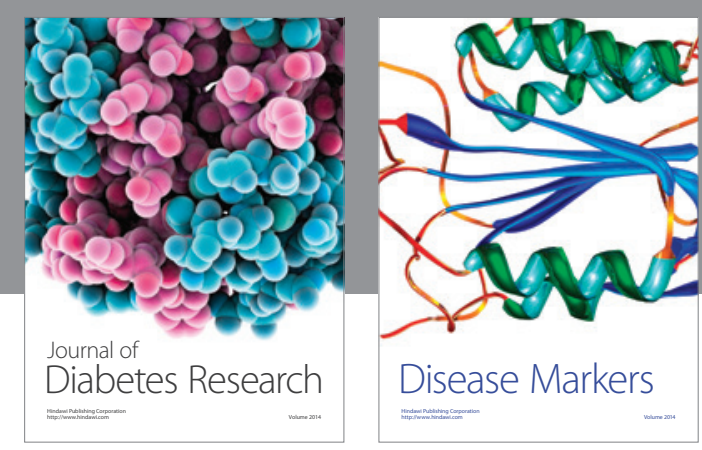

Disease Markers
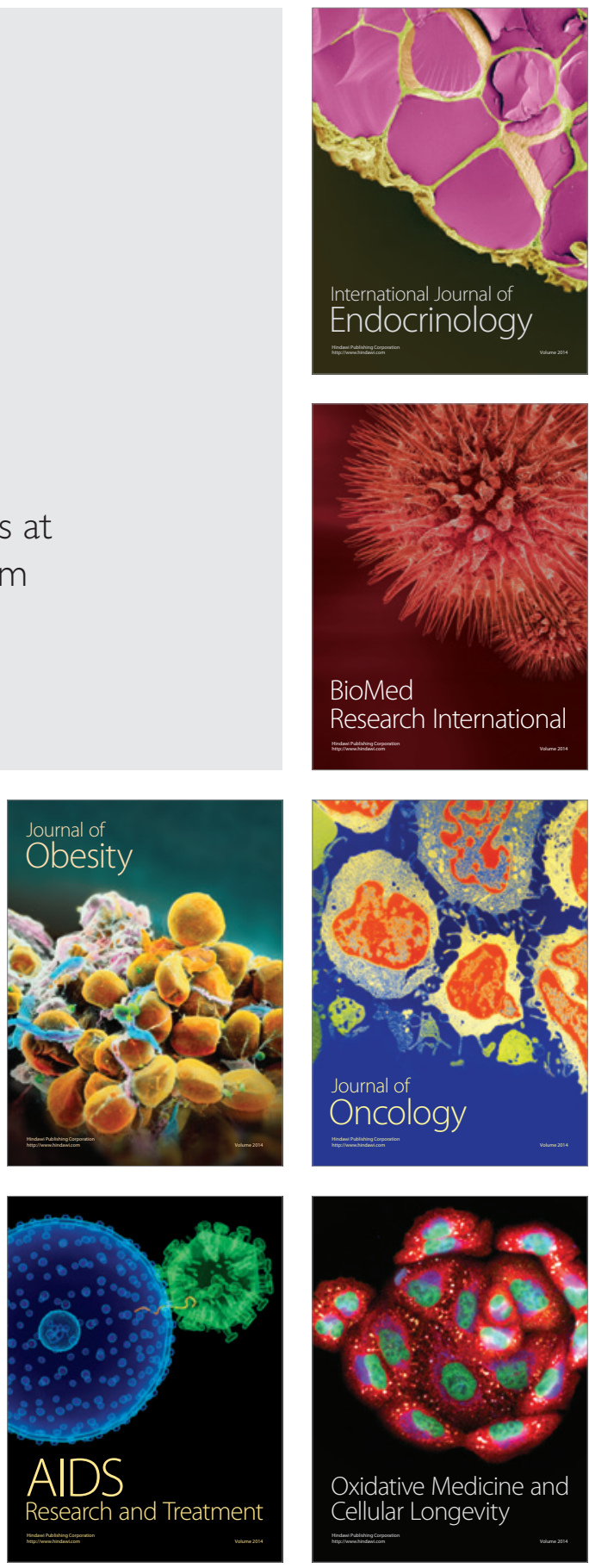